\title{
Selected Nature-Inspired Algorithms in Function of PM Synchronous Motor Cogging Torque Minimisation
}

Research Article

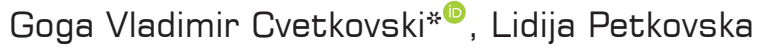 \\ Ss.Cyril and Methodius University, Faculty of Electrical Engineering and Information Technologies, Skopje, North Macedonia
}

Received: August 01, 2021; Accepted: September 21, 2021

\begin{abstract}
Both permanent magnet brushless DC motors and permanent magnet synchronous motors have attracted wide attention and are increasingly used in industrial high-performance applications in recent years. Those motors are known for their good electrical, magnetic and performance characteristics, but there is one parameter known as cogging torque that has a negative influence on the performance characteristics of the motor. This pulsating torque is generated as a result of the interaction between the stator teeth and the permanent magnets. The minimisation of the ripple of this torque in those permanent magnet motors is of great importance and is generally achieved by a special motor design which in the design process involves a variety of many geometrical motor parameters. In this research work, a novel approach will be introduced where two different nature-inspired algorithms, such as genetic algorithm (GA) and cuckoo search (CS) algorithm are used as an optimisation tool, in which the defined equation for the maximum value of the cogging torque is applied as an objective function. Therefore, a proper mathematical presentation of the maximum value of the cogging torque for the analysed synchronous motor is developed and implemented in the research work. For a detailed analysis of the three different motor models, the initial motor and the two optimised motor models are modelled and analysed using a finite element method approach. The cogging torque is analytically and numerically calculated and the results for all the models are presented.
\end{abstract}

Keywords: permanent magnet synchronous motor • optimisation methods $\bullet$ cogging torque $\bullet$ genetic algorithm • finite element method

\section{Introduction}

The permanent magnet motors, due to their good performance characteristics and features, such as high torque density, high efficiency and high power-volume ratio have been used in high-performance industrial drives. Unfortunately, the presence of cogging torque in these types of motors throws a shadow on their performance characteristics, especially in applications sensitive to torque ripple. In practice, in these types of motors, two types of sources generate the torque ripple:

- The cogging effect that is produced as a result of the interaction between the rotor magnetic flux and variable permeance of the air gap due to the geometry of stator slots;

- Torque ripple generated as a result of the drive operation.

Generally speaking in literature there are two types of approaches to reduce the cogging torque effect in permanent magnet motors. The first approach is dedicated to a minimisation of the cogging torque by a direct approach by changing the motor design parameters each at a time (Bianchi and Bolognani, 2002, 2000; Islam et al., 2004; Zhu and Howe (2000)). The previously mentioned approach includes proper magnet pole arc design, skewing of rotor magnets or stator core, step skew of the magnets, dummy slots, permanent magnet shifting, proper definition of stator slots/rotor pole combination, etc. (Fei and Luk, 2010; Ishikawa and Slemon, 1993; Islam et al., 2004; 
Li and Slemon, 1988; Ma et al., 2018; Siregar et al., 2019; Zhu and Howe (2000)). Such an approach involves a wide range of investigations and calculations and an analysis of a large number of solutions. The methods that have been reported so far in literature involves performing the minimisation of the cogging torque at the expense of added complexity of stator or rotor magnet construction that results in some loss of output torque. The second approach is analytical and it is devoted to an analytical definition of the cogging torque function that can be used afterwards to reduce the cogging torque by changing some of the motor parameters (Kang and Hur, 2005; Wu et al. (2012); Zarko et al., 2008). where in others the work is focused on the determination of a function that can be used to evaluate the value of the cogging torque (Ackermann et al., 1992; Deodharet al., 1996; Goto and Kobayashi, 1983; Gieras, 2004; Ishikawa and Slemon, 1993; Li and Slemon, 1988).

The aim of this paper is to investigate the design parameters that influence the cogging torque and develop a strategy to minimise the torque ripple by using an analytical calculation of the cogging torque and combine it with an optimisation procedure.

Therefore, in this paper, the authors are proposing a novel approach in which two nature-inspired optimisation methods, are involved towards minimisation of the analytically defined cogging torque function. It is estimated that there are over 100 different nature-inspired optimisation algorithms used in different areas (Mirjaliliet al., 2020; Yang, 2014) that can be found in literature nowadays and their number is increasing all the time. The motivation for this work was to explore the possibility of applying selected methods in the cogging torque reduction of the investigated permanent magnet synchronous motor. In such a way the design procedure aiming towards a reduced cogging torque can be done much faster and much easier. The applied optimisation methods for this research work are genetic algorithm (GA) and cuckoo search (CS). The decision to use those two optimisation techniques is based on the good performance of the selected methods in other or similar optimisation procedures found in literature, from which only selected works are presented. (Benlamine et al., 2013; Chitara et al., 2018; Eom et al., 2001; Kumar and Chakarverty, 2011; Mirahki et al., 2014; Uler et al., 1995). GA was quite successfully also used in the optimisation of the cogging torque using different approaches. (Ho et al., 2010; Kamal et al., 2017; Kang and Hur, 2005; Sun et al., 2019). An additional motivation for this work is to investigate how CS will perform in the area of cogging torque optimisation. In the text that follows a brief introduction of the two methods is given. In those optimisation methods, the cogging torque function is defined as an objective function.

\section{Cogging Torque Definition}

As it was mentioned previously the cogging torque is a function of the rotor position and therefore has higherorder harmonic components that make the cogging torque formulation difficult to optimise. While investigating the different approaches in the formulation of the cogging torque we came across the work of Gieras (2004) that was an inspiration for this work. In this work, the definition of the cogging torque is quite simple and defined in function of the basic motor parameters. Such a definition of the peak value of the cogging torque can be easily used as an objective function in an optimisation process (Cvetkovski and Petkovska, 2021). The simplified version of the formulation of the peak value of the cogging torque which is the objective function of the optimisation, is presented by Eq. (1):

$$
\text { Objective function }=T_{\text {cogging }}=\frac{g \cdot L \cdot D_{1 \text { in }}}{4 \cdot \mu_{o}} \cdot A_{T} \cdot \frac{B_{g}}{k_{c}}
$$

where: $g$ is the air gap length, $L$ is the axial length of the motor, $D_{1 i n}$ is stator inner diameter, $A_{T}$ is a motor coefficient, $B_{g}$ is the average air gap flux density and kc is Carter's coefficient. The coefficient AT is equal to $A_{T}=2 k_{s k}{ }^{2} k_{o k}{ }^{2}\left(g / \tau_{s}\right)$ $B_{g}$, where $k_{s k}$ is a stator skew factor, $k_{o k}$ is a stator opening slot factor and $\tau_{s}$ is the stator slot pitch. In the text that follows a detailed presentation of each parameter shown in Eq. (1) will be presented, as well as a presentation of the parameters that will appear in the other equations. Therefore, Carter's coefficient $k_{c}$ is defined as:

$$
k_{c}=\frac{1}{1-\frac{1}{\frac{\tau_{s}}{b_{s o}}} \cdot\left(5 \cdot \frac{g_{c}}{b_{s o}}+1\right)}
$$


where: $b_{s o}$ is the stator slot opening, $g_{c}=g+h_{m} / \mu_{r}$ is the average air gap, $\mu_{r}$ is the relative permeability of the permanent magnets and $\tau_{\mathrm{s}}$ is the stator slot pitch in the air gap that is equal to:

$$
\tau_{s}=\left(R_{r o}+h_{m}+g\right) \cdot \frac{2 \pi}{Z}
$$

in which $R_{r o}$ is the outside radius of the rotor core and is one of the optimised parameters. $Z$ is the total number of stator slots and $h_{m}$ is the height of the permanent magnet in the radial direction. For this type of motor, the value of the air gap flux density can be calculated using the following equation:

$$
B_{g}=\frac{C_{f} \cdot B_{r}}{1+\mu_{r} \cdot k_{c} \cdot \frac{k_{m l}}{P_{c}}}
$$

where: $B_{r}$ is the residual flux density of the permanent magnets, $k_{m l}$ is the flux leakage coefficient and $C_{f}$ is the flux concentration coefficient and is defined as:

$$
C_{f}=\frac{2 \cdot f_{m}}{1+f_{m}}
$$

In which $f_{m}$ is the permanent magnet fraction and it is also one of the optimised motor parameters. $P_{c}$ is the motor permeability coefficient and it is defined as:

$$
P_{c}=\frac{h_{m}}{g \cdot C_{f}}
$$

Finally, the flux leakage coefficient $k_{m l}$ can be expressed with the following equation:

$$
k_{m l}=1+\frac{4 \cdot l_{m}}{\pi \cdot \mu_{r} \cdot f_{m} \cdot \tau_{P M}} \cdot \ln \left[1+\frac{\pi \cdot g}{\left(1-f_{m}\right) \cdot \tau_{P M}}\right]
$$

In Eq. (7) $\tau_{P M}$ is the pole pitch along the outer rotor line and all the other parameters are defined previously. This parameter can be determined using the following equation:

$$
\tau_{P M}=\frac{2 \pi \cdot R_{R o}}{N_{P M}}
$$

In Eq. (8) $R_{r o}$ is the outer rotor core radius and it is one of the variable parameters presented in Figure 1 and $N_{P M}$ is the total number of permanent magnets mounted on the rotor core.

The investigated object is a brushless three-phase synchronous permanent magnet motor produced by the company Koncar in Croatia. The motor has a laminated stator with 36 slots and a rotor with 6-skewed SmCo5 surface-mounted permanent magnets with $B_{r}=0.95 \mathrm{~T}$. The rated data of the motor are: $I=18 \mathrm{~A}, T=10 \mathrm{Nm}$ and $n=1,000$ rpm @ $50 \mathrm{~Hz}$.

According to the simplified cogging torque equation of PMSM, some of the motor parameters are chosen to be constant and some are variables. The variable parameters that are varied through the optimisation are outside radius of the rotor core $R_{r o}$, air-gap length $g$, permanent magnet fraction $f_{m}$, magnet height $h_{m}$, motor axial length $L$, and stator slot opening $b_{s}$, as shown in Figure 1. The other design parameters of the motor (especially in the stator regain) are in relation to optimisation parameters that enable the optimisation to be performed on the whole motor with fewer design variables and with parameters that are related among themselves. 


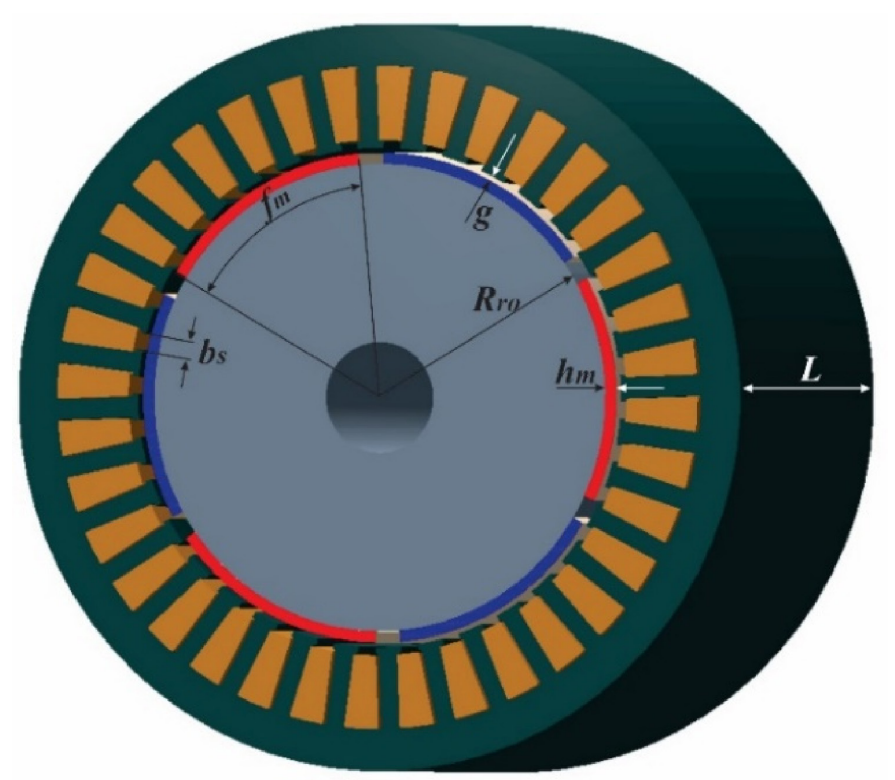

Fig. 1. Presentation of PMSM optimisation parameters. PMSM, permanent magnet sunchronous motor.

Table 1. Optimisation constraints

\begin{tabular}{lcc}
\hline Description & Parameters & Value, unit \\
\hline \hline Torque & $T(\mathrm{Nm})$ & 10 \\
Number of phases & $N_{p h}$ & 3 \\
PM residual flux density & $B_{r}(\mathrm{~T})$ & 0.95 \\
Number of PM & $N_{m}$ & 6 \\
Number of stator slots & $Z$ & 36 \\
Stator back iron flux density & $B_{m b i}(\mathrm{~T})$ & $\leq 1.5$ \\
Stator teeth flux density & $B_{m s t}(\mathrm{~T})$ & $\leq 1.5$ \\
Stator steel mass density & $\rho_{s t}\left(\mathrm{~kg} / \mathrm{m}^{3}\right)$ & 7,300 \\
PM mass density & $\rho_{P M}\left(\mathrm{~kg} / \mathrm{m}^{3}\right)$ & 7,400 \\
Rotor steel mass density & $\rho_{\text {rot }}\left(\mathrm{kg} / \mathrm{m}^{3}\right)$ & 7,300 \\
Copper mass density & $\rho_{C u}\left(\mathrm{~kg} / \mathrm{m}^{3}\right)$ & 8,930 \\
\hline PM, perman & &
\end{tabular}

PM, permanent magnet.

The optimisation constraints used in the optimal design of the PMSM are divided into two groups, such as constraints that are geometrical, and other constraints that take into account the motor performance and material characteristics. The constraints are presented in Table 1. The constraints help to reduce the number of independent optimisation variables and put a focus only on the objective function. Some motor parameters are obtained analytically and others are determined by measurements and also analytically. Most of the analytically calculated parameter values are in good agreement with the measured ones, which proves that the mathematical model of the motor is quite realistic and close to the physical motor model. This is very important for the quality of the optimisation process and the quality of the proposed solutions.

\section{Presentation of Nature Based Methods and Optimization Results}

The optimisation methods that are used for the minimisation of the cogging torque are nature-inspired. They are also direct search methods in which the optimisation movement through the investigated area is governed by individual nature-based parameters, as well as on the value of the objective function. 


\subsection{Genetic algorithm}

GA in general are an evolutionary-based stochastic optimisation algorithm with a global search potential proposed by Holland in 1975 (Holland, 1995). So far, GAs have proven to be among the most successful class of algorithms under evolutionary-based algorithms which are inspired by the evolutionary ideas of natural selection. They are based on the theory of survival of the fittest. The outstanding performance of this method in the optimisation process is because the method search is based on the value of the objective function and not on the values of the optimisation parameters. The algorithm starts the optimisation search by a randomly initialised population of solutions (chromosomes). The chromosome is actually a vector of real or binary numbers that represent the solutions for each optimisation variable. During the optimisation in each generation for the whole population, the algorithm calculates the fitness value for each chromosome using an appropriate fitness function suitable for the problem. Based on those values, the best chromosomes are selected into the mating pool, where they undergo a cross-over and mutation within the population as a result of which at the end a new set of solutions (offspring) is generated. The block diagram of the GA is presented in Figure 2. The quality of the GA search is based on the three major genetic operators that involve selection, crossover and mutation. The considered values of the GA parameters for this optimisation problem are population size $N=20$, crossover probability $p_{c}=0.85$ and mutation probability $p_{m}=0.07$. To improve the quality of the search fitness scaling and elitism are introduced. The function fitness scaling is levelling the best and the worst solutions in a population by which an equal chance of survival is given to all the members of the population. With this function, the premature reach of an optimal solution is prevented. The function elitism is taking care of the best solution to be automatically transferred to the next generation. This method over the years has been implemented in many areas of optimisation and also on many electrical machines in their optimal design using different objective functions (Lukaniszyn et al., 2004).

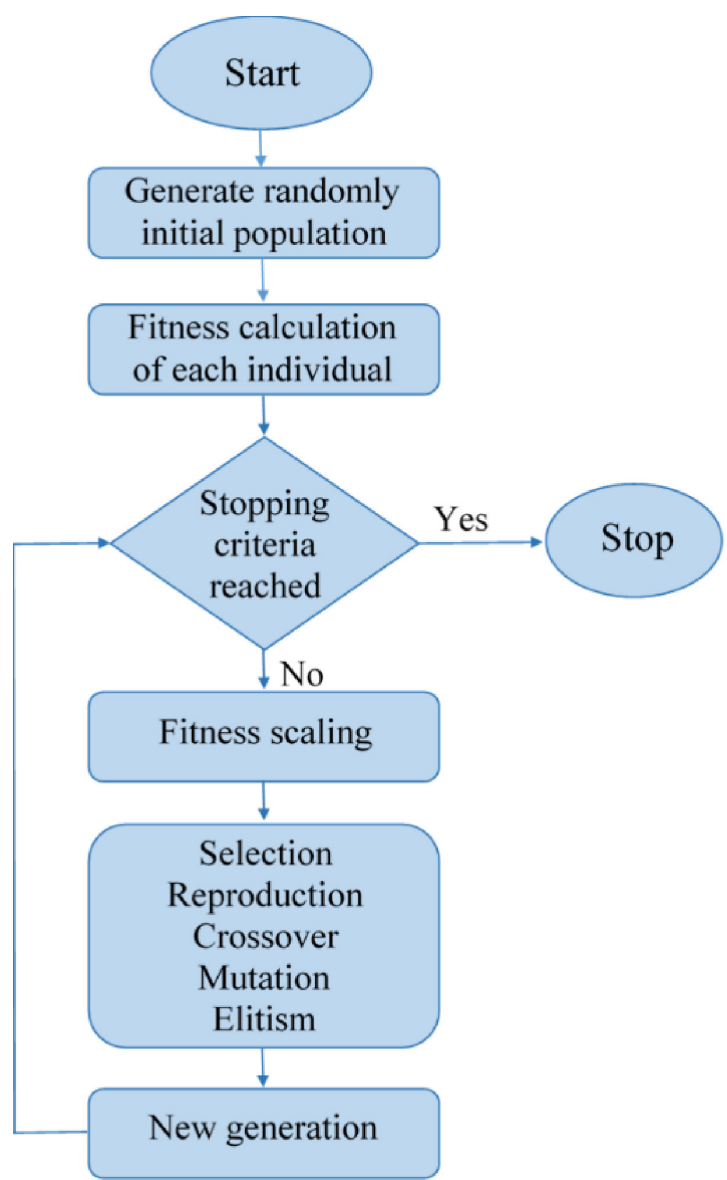

Fig. 2. Block diagram of the main steps of the GA. GA, genetic algorithm. 
Table 2. Optimisation boundaries and results

\begin{tabular}{lllll}
\hline Parameters & Lower bound & Upper bound & Initial model & GA solution \\
\hline \hline$R_{\text {ro }}(\mathrm{m})$ & 0.0378 & 0.0442 & 0.042 & 0.0422 \\
$f_{m}(/)$ & 0.81 & 0.99 & 0.9 & 0.855 \\
$h_{m}(\mathrm{~m})$ & 0.0018 & 0.0022 & 0.002 & 0.0019 \\
$g(\mathrm{~m})$ & 0.00072 & 0.00088 & 0.0008 & 0.00084 \\
$L(\mathrm{~m})$ & 0.081 & 0.099 & 0.09 & 0.0855 \\
$b_{s}(\mathrm{~m})$ & 0.0027 & 0.0033 & 0.003 & 0.00285 \\
$T_{\text {cogging }}(\mathrm{Nm})$ & & & 0.925 & 0.767 \\
\hline
\end{tabular}

$\mathrm{GA}$, genetic algorithm.

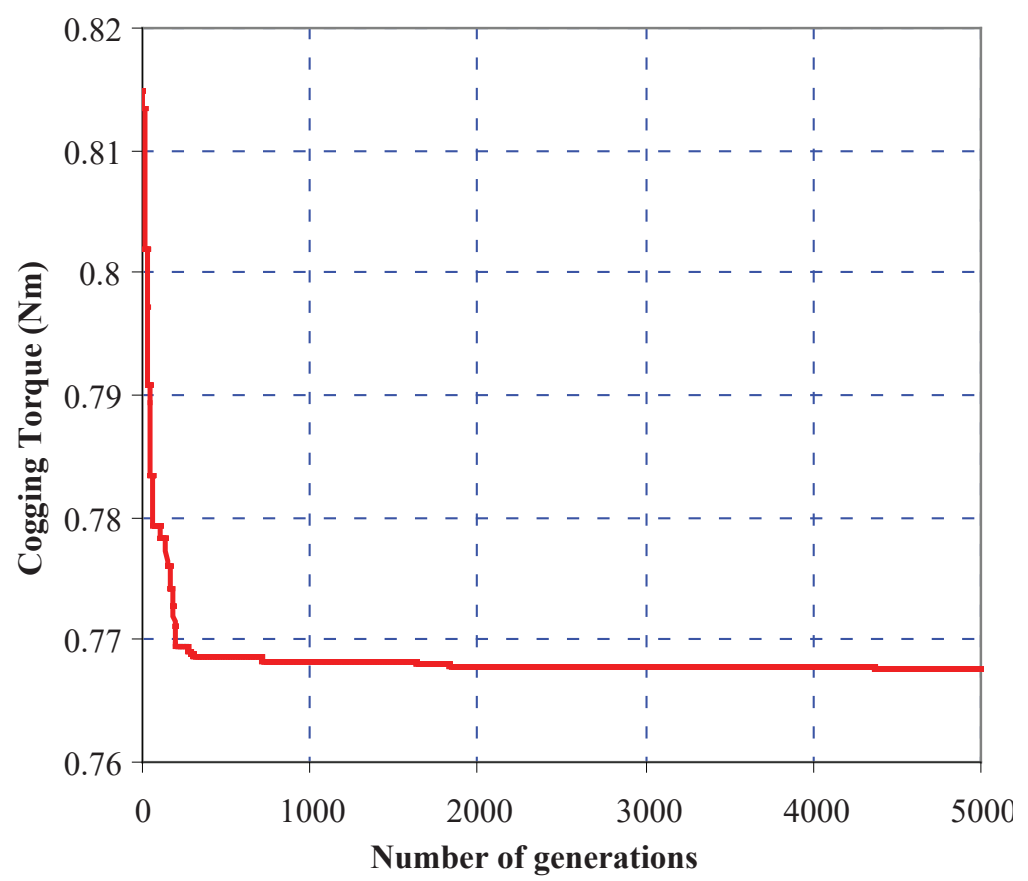

Fig. 3. Cogging torque change during GA search during generations. GA, genetic algorithm.

The algorithm created for the optimal design of the PMSM uses real number representation, arithmetic crossover and linear fitness scaling as an improvement and reliability of the GA search. The lower and upper bound as well as the cogging torque results and the values of the optimisation parameters of the optimisation procedure, concerning the initial model, are presented in Table 2.

The convergence of the value of the cogging torque of the motor as an objective function during the GA optimisation search for 5,000 generations is shown in Figure 3. The minimal value of the cogging torque that has been reached after the optimisation is 0.767 , which is a reduction of the cogging torque of about $17.08 \%$ in comparison to the value of 0.925 of the initial solution.

\subsection{Cuckoo search}

CS algorithm is also a population-based stochastic global search algorithm. In the CS algorithm, the potential solutions correspond to the Cuckoo bird eggs in nature. The natural system of the cuckoo birds is quite complex and therefore a simplification of the system is necessary for successful implementation in a computer algorithm for 
practical optimisation purposes. The simplification of the Cuckoo bird behaviour into a CS algorithm is realised by taking into account the following three approximation rules:

- Cuckoos chose a random location (nest) for laying their eggs. The artificial cuckoo bird in the algorithm can lay only one egg at a time.

- Elitism in the selection process is applied, so only the eggs with highest quality are passed to the next generation.

- Host nests number is not adjustable. Host bird discovers cuckoo egg with probability $p_{d} \in[0,1]$. If the cuckoo egg is disclosed by the host, it may be thrown away, or the host may abandon its own nest and commit it to the cuckoo intruder. A simple representation where one egg in a nest represents a solution and a cuckoo egg represents a new solution is used here. The aim is to use the new and potentially better solutions (cuckoo eggs) to replace worse solutions that are in the nests. (Yang and Deb, 2010).

In this optimisation algorithm the same objective function, as well as the same optimisation parameters, as in the previous GA optimisation algorithm are implemented. The block diagram of the CS algorithm is presented in Figure 4.

The optimisation process has been repeated many times and the results for the best solution are presented in Table 3, and the convergence of the value of the cogging torque as an objective function is presented in Figure 5.

The final minimal value of the cogging torque that has been reached is $0.729 \mathrm{Nm}$ and this value represents a reduction of the maximum value of the cogging torque of about $21 \%$ concerning the initial solution. This value shows a reduction of the cogging torque in relation to the GA solution of about $5 \%$.

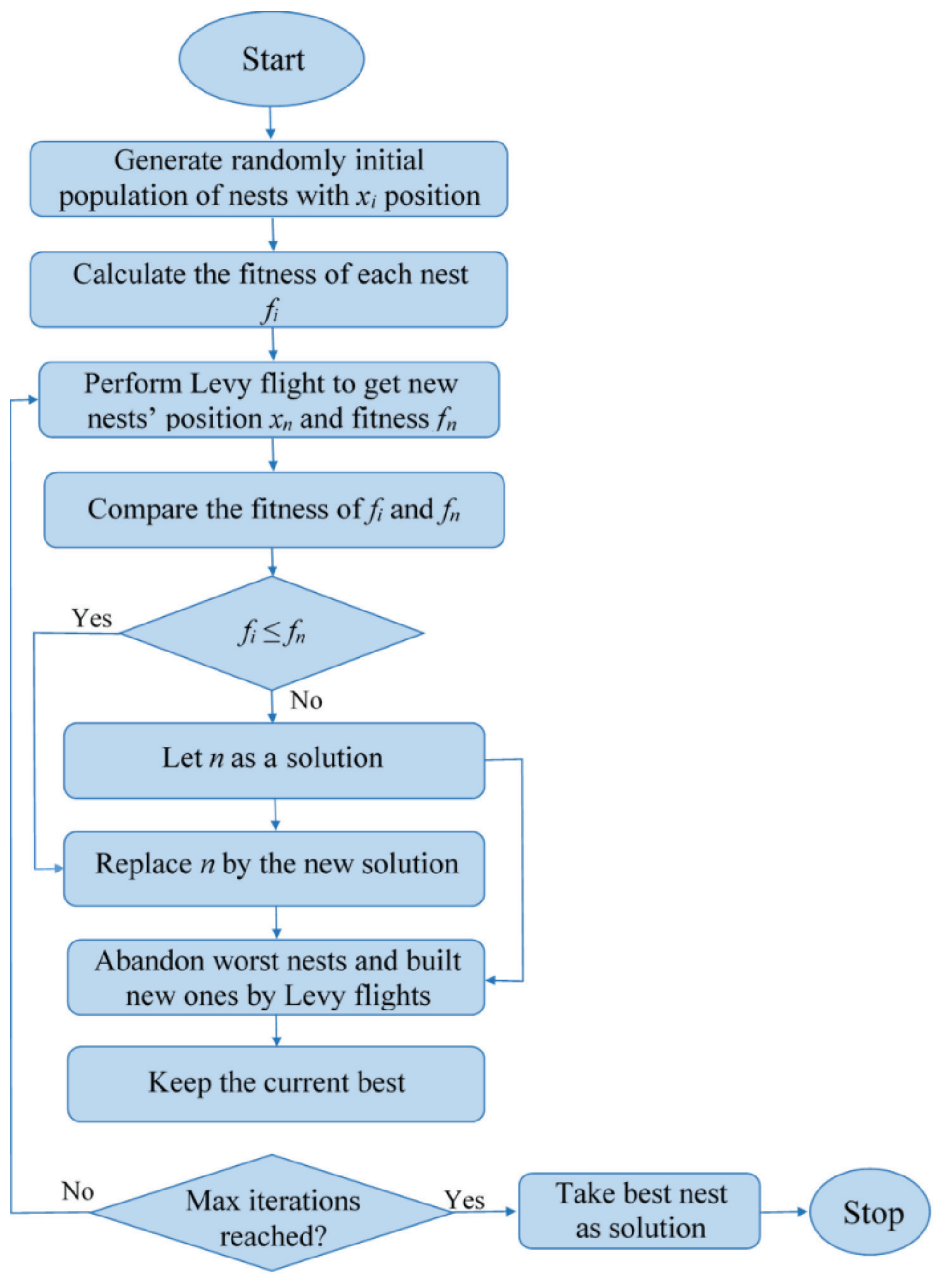

Fig. 4. Block diagram of the main steps of the CS algorithm. CS, cuckoo search. 
Table 3. Optimisation boundaries and results

\begin{tabular}{lcccc}
\hline Parameters & Lower bound & Upper bound & Initial model & CS solution \\
\hline \hline$R_{\text {ro }}(\mathrm{m})$ & 0.0378 & 0.0442 & 0.042 & 0.038 \\
$f_{m}(/)$ & 0.855 & 0.945 & 0.9 & 0.855 \\
$h_{m}(\mathrm{~m})$ & 0.0019 & 0.0021 & 0.002 & 0.0019 \\
$g(\mathrm{~m})$ & 0.00076 & 0.00084 & 0.0008 & 0.00084 \\
$L(\mathrm{~m})$ & 0.0855 & 0.0945 & 0.09 & 0.0855 \\
$b_{s}(\mathrm{~m})$ & 0.00285 & 0.00315 & 0.003 & 0.00285 \\
$T_{\text {cogging }}(\mathrm{Nm})$ & & & 0.925 & 0.729 \\
\hline
\end{tabular}

CS, cuckoo search.

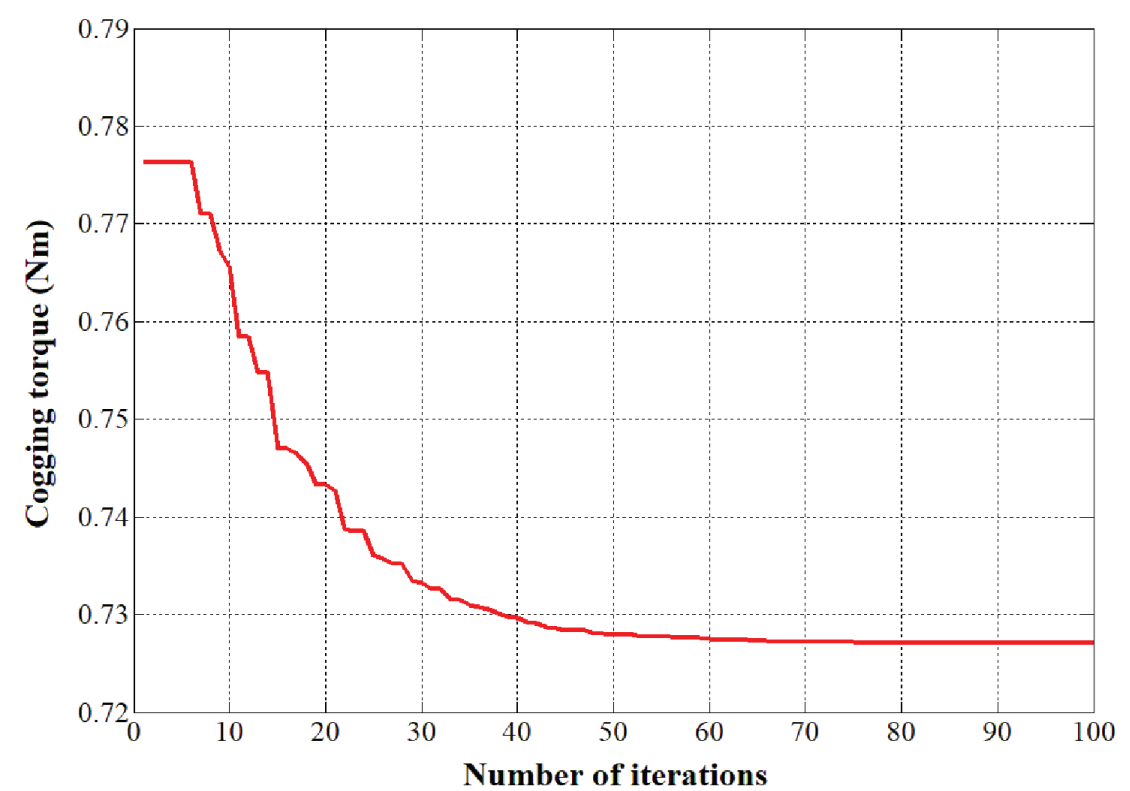

Fig. 5. Cogging torque change during CS iterations. CS, cuckoo search.

In this research work, the minimisation of the cogging torque is not the only parameter that will be analysed. Therefore, in Table 4, the values of other important motor parameters for the three models are presented.

From the presented data in Table 4, it can be concluded that besides the reduction of the cogging torque value, also other motor parameters are improved in the optimised solutions concerning the initial model, and others, unfortunately, reach worse values. This is because the optimisation is carried out for the cogging torque only and not taking into account the other motor parameters. Due to the change in the dimensions of the motor especially the dimensions of the stator core some parameters, such as total copper mass, suffer more concerning other parameters due to the increase of the number of turns in one section and due to the increase of the stator wire diameter that in overall increases the copper mass. The comparative analysis of the three motor models is going to be extended by using the commercial programme Motor-Solve by Infolytica (Infolytica, 2017) that is based on the finite element method. The application of finite element analysis has been established as a standard procedure in the motor analysis because it gives a good overview of the analysed motor as well as good results that can be used in the comparative analysis (Quintal-Palomo et al., 2016). Using this programme first the cogging torque for the three solutions is going to be calculated. Other motor characteristics, such as air gap flux density and electromagnetic torque are going to be calculated and presented, as well. 
Table 4. Comparative motor parameters

\begin{tabular}{|c|c|c|c|c|}
\hline Parameters & Description & Initial model & GA solution & CS solution \\
\hline$B_{g}(\mathrm{~T})$ & Avg. air gap flux density & 0.630 & 0.600 & 0.599 \\
\hline$m_{F e}(\mathrm{~kg})$ & Total iron mass & 6.128 & 5.653 & 5.165 \\
\hline$m_{P M}(\mathrm{~kg})$ & Total PM mass & 0.318 & 0.2725 & 0.245 \\
\hline$m_{\mathrm{Cu}}(\mathrm{kg})$ & Total copper mass & 1.5979 & 15.486 & 21.305 \\
\hline$W_{s}$ & Number of turns in one section & 9 & 10 & 11 \\
\hline I (A) & Phase current & 17.41 & 17.306 & 17.438 \\
\hline$R_{75^{\circ}}(\mathrm{ohm})$ & Phase resistance & 0.150 & 0.162 & 0.145 \\
\hline$P_{\mathrm{Cu}}(\mathrm{W})$ & Ohmic losses & 136.315 & 145.183 & 132.123 \\
\hline$P_{F e}(\mathrm{~W})$ & Iron losses & 16.233 & 14.544 & 14.594 \\
\hline$d_{w}(\mathrm{~mm})$ & Stator wire diameter & 1.88 & 1.98 & 2.26 \\
\hline Eff & Efficiency & 0.8571 & 0.8521 & 0.8612 \\
\hline
\end{tabular}

CS, cuckoo search; GA, genetic algorithm.

\section{Motor-Solve Analysis}

In the Motor-Solve programme (Motor-Solve and Infolytica, 2017), proper modelling of the three motor models is performed. All the necessary data regarding the dimensions, materials, supply and load are applied for all three analysed motor models. The first parameter that has been calculated is the cogging torque. The comparative values of the analytically and numerically determined peak values of the cogging torque are presented in Table 5 . The shape of the cogging torque for the initial model, GA and CS solutions are presented in Figures 6a-c, respectively. From the presented values in Table 5 and the characteristics, it can be concluded that the analytically determined values of the cogging torque correspond to the values determined from the numerical calculation using the Finite element method. This proves the quality of the mathematical model of the cogging torque implemented in the optimisation algorithms. The rather small decrease of the peak value of the cogging torque of the optimised solutions concerning the initial model is because the optimised parameters are not allowed to change in a wide range and also because skewing is not taken under consideration.

The next motor parameter that is going to be presented and compared is the air gap flux density distribution for all three motor models. The average values of the air gap flux density calculated analytically are presented in

Table 5. Cogging torque values

\begin{tabular}{llccc}
\hline Parameters & Type of calculation & Initial model & GA solution & CS solution \\
\hline \hline$T_{\operatorname{cog}}(\mathrm{Nm})$ & Analytical & 0.9245 & 0.7675 & 0.7292 \\
$T_{\operatorname{cog}}(\mathrm{Nm})$ & Numerical & 0.925 & 0.767 & 0.729 \\
\hline
\end{tabular}

CS, cuckoo search; GA, genetic algorithm.

A

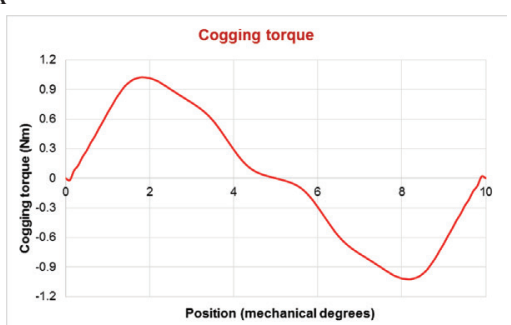

B

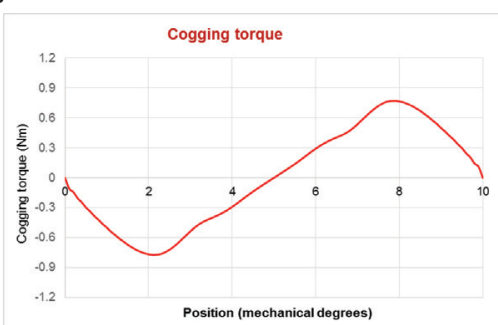

C

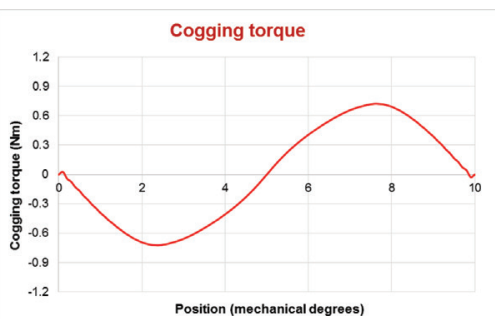

Fig. 6. (a) Cogging torque characteristics for the initial model. (b) Cogging torque characteristics for the GA solution. (c) Cogging torque characteristics for the CS solution. CS, cuckoo search; GA, genetic algorithm. 
A

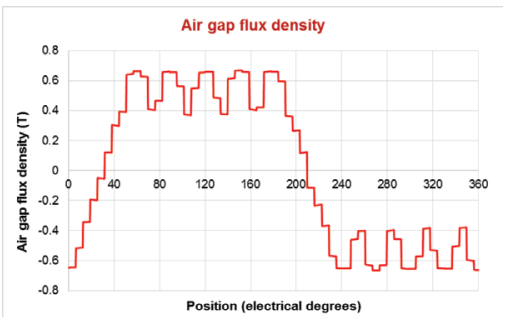

B

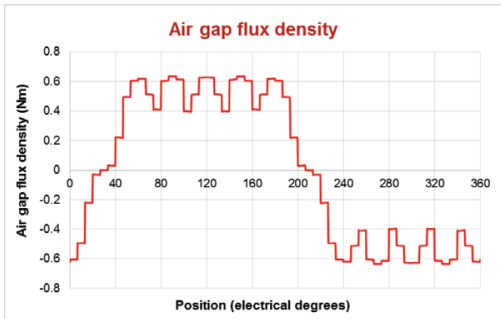

C

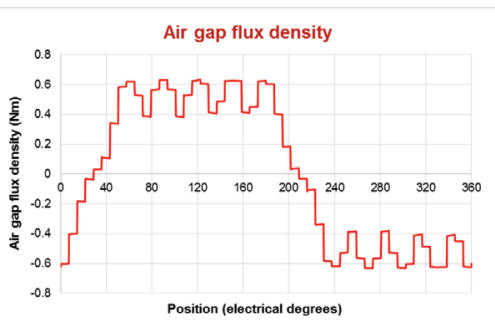

Fig. 7. (a) Air gap flux density distribution for the initial model. (b) Air gap flux density distribution for the GA solution. (c) Air gap flux density distribution for the CS solution. CS, cuckoo search; GA, genetic algorithm.

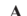

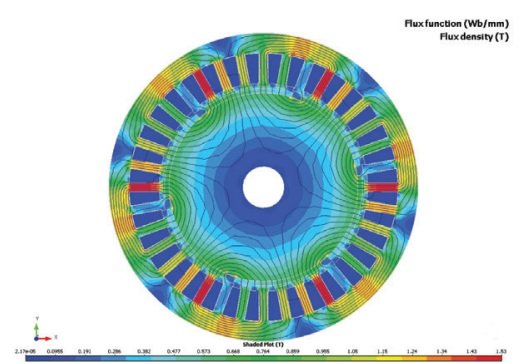

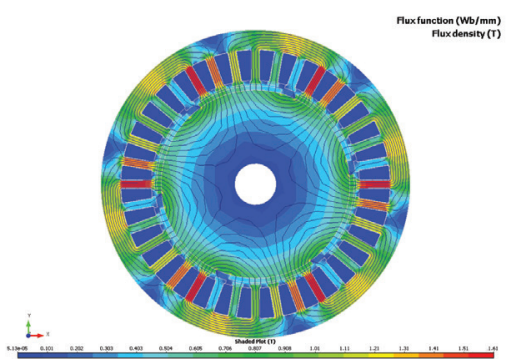

Fig. 8. (a) Magnetic field distribution for the initial model. (b) Magnetic field distribution for the GA solution. (c) Magnetic field distribution for the CS solution. CS, cuckoo search; GA, genetic algorithm.

A

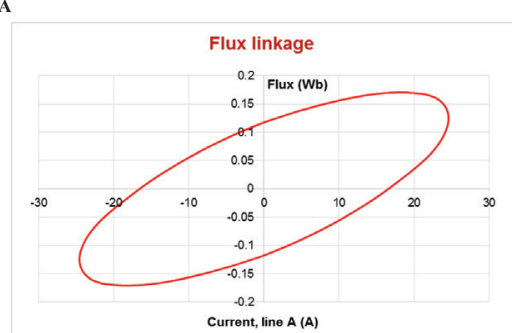

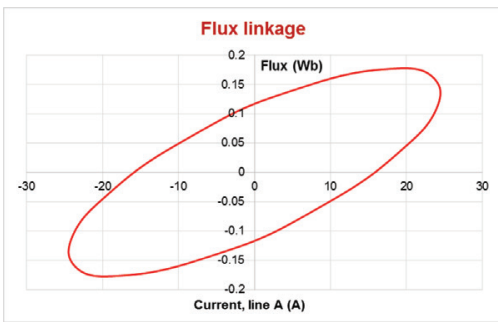

C

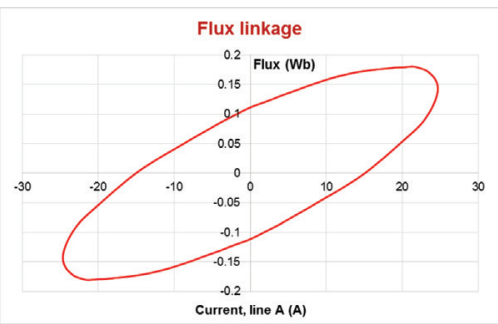

Fig. 9. (a) Flux linkage vs. current characteristics for the initial model. (b) Flux linkage vs. current characteristics for the GA model. (c) Flux linkage vs. current characteristics for the CS model. CS, cuckoo search; GA, genetic algorithm.

A

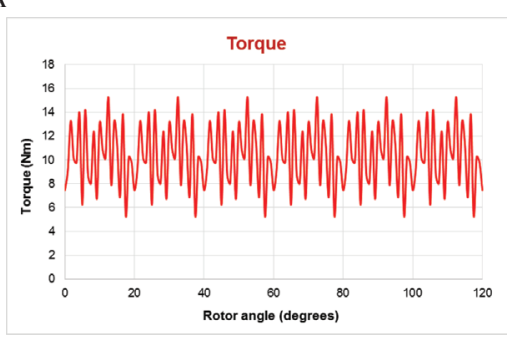

B

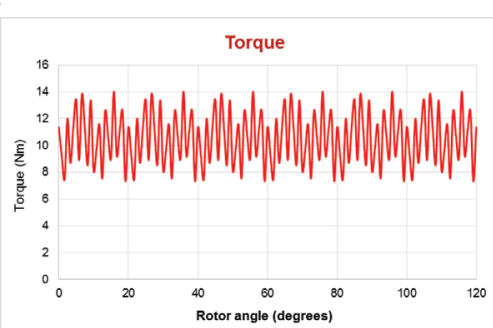

C

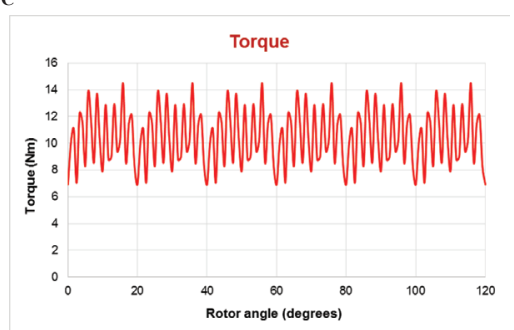

Fig. 10. (a) Torque characteristics for the initial model. (b) Torque characteristics for the GA solution. (c) Torque characteristics for the CS solution. CS, cuckoo search; GA, genetic algorithm.

Table 4. From the presented air gap flux density distribution and the analytically calculated average values, it can be concluded that there is also a good agreement between those values. The flux density pulsations that are visible in all three distributions are due to the influence of the teeth and slots on its distribution .

The air gap flux density distribution for the investigated three models is presented in Figures 7a-c. The magnetic field distribution in the motor can be also determined using the previously mentioned programme. Based on the 

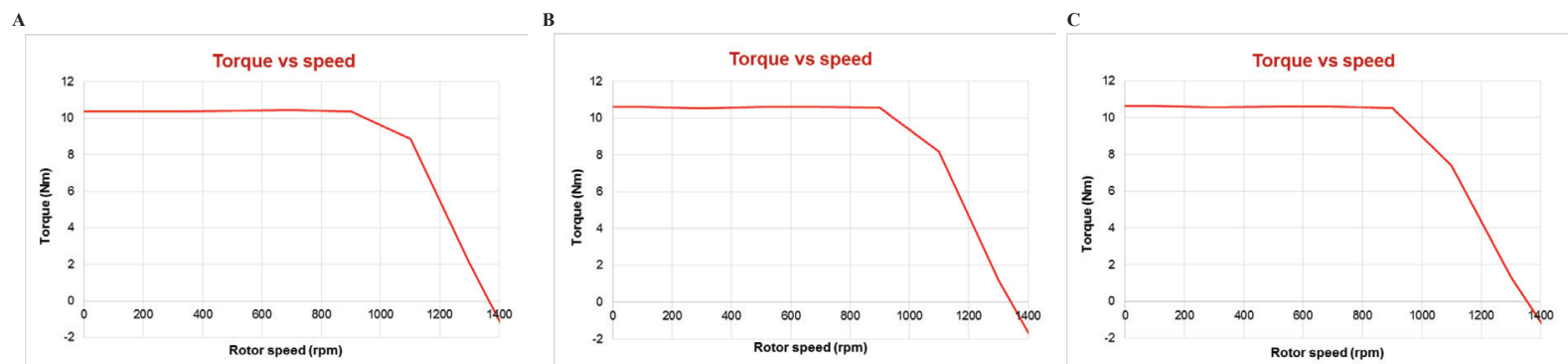

Fig. 11. (a) Torque-speed characteristics for the initial model. (b) Torque-speed characteristics for the GA solution. (c) Torque-speed characteristics for the CS solution. CS, cuckoo search; GA, genetic algorithm; GA, genetic algorithm.

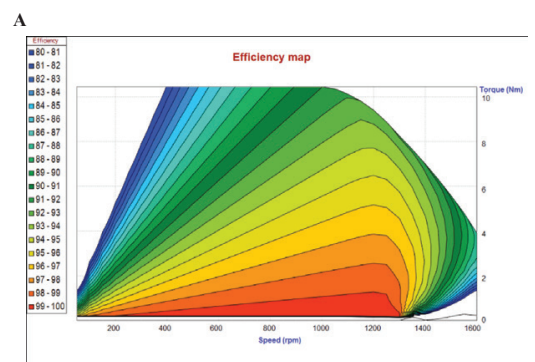

Fig. 12. (a) Efficiency map for the initial model. GA, genetic algorithm.
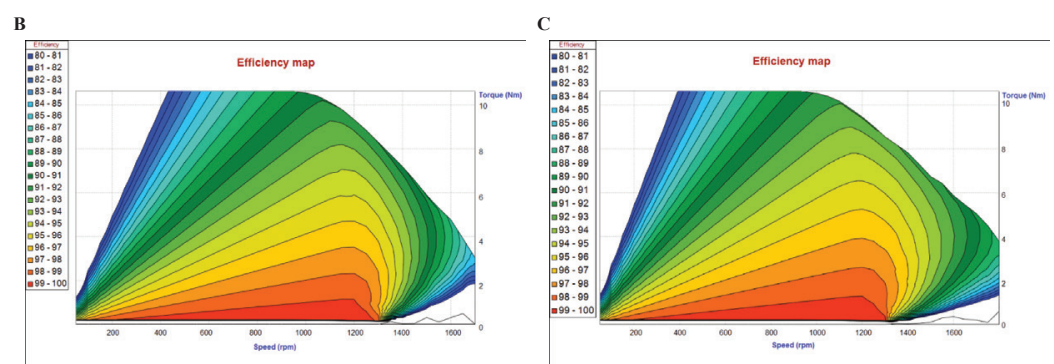

presented distributions, especially for the optimised solutions, it can be concluded that the values of the flux density in the segments of the motor of special interest (stator core, stator teeth, etc.) are in good agreement with the values prescribed or calculated during the optimisation process. The magnetic field distribution for the three models is presented in Figures 8a-c.

Another interesting parameter that is determined and is going to be presented in this material is the flux linkage that will be shown as a diagram of the dependence of the flux linkage of the line current. This relation is presented for all three analysed models, the initial model, GA model and CS model, in Figures 9a-c, respectively. From the presented characteristics it can be noticed that there is a small change in the shape and the values of the graph that is due to the change of the size of the permanent magnets that influences the average value of the air gap flux density in the air gap shown in Table 4. This change in the air gap flux results in a change in the value of the line current in order for the motor to be able to develop the defined rated torque.

Two other motor characteristics that can be determined using the Motor-Solve programme are the torque and the Torque-speed characteristics. For this analysis, the two characteristics have been calculated and presented in the following text for all three analysed motor models. In the analysis, it has been taken into consideration the fact that the motor is supplied via an inverter. The presentation of the developed torque for the three motor models is presented in Figures 10a-c. On the other hand, the Torque-speed characteristics for the analysed models are presented in Figures 11a-c.

From the presented torque characteristics it can be concluded that there is a reduction of the pulsations of the electromagnetic torque of the optimised solutions concerning the initial motor model, which is a result of the reduction of the cogging torque realised through the optimisation process. On the other hand, the torque-speed characteristic of the two optimised solutions shows a minor decrease concerning the initial solution.

At the end of this material, a presentation of the efficiency map of the three motor models is shown. The calculation of the efficiency is done by the software in which all the material properties are included in the modelling process. The software takes into consideration all the losses in the motor and they are calculated automatically for a defined working regime. The efficiency map for all three investigated models for different speeds and loads is presented in Figures 12a-c. From the graphs, it can be concluded that the efficiency map of both optimised solutions is improved concerning the initial model.

Based on the presented numerical results it can be concluded that the mathematical model for the cogging torque determination as well as for the analytical evaluation of the models is quite adequate. The analytically 
determined values of the motor parameters are in good agreement with the numerically calculated and presented values.

Finally, based on all previously presented data it can be concluded that the two optimised models have not only smaller cogging torque values in comparison with the initial solution but also have an improved motor performance characteristic, such as torque, torque-speed characteristics and efficiency as the most important parameter that improves the overall performance of the motor and reduces the power consumption and improves the energy efficiency of the motor.

\section{Conclusion}

In this paper, the authors are giving a brief presentation, as well as implementation, of two novel techniques for optimisation (minimisation) of the cogging torque value of permanent magnet synchronous motor. The selected and implemented optimisation methods are GA and CS. The cogging torque of the motor has been selected as an objective function in the optimisation process. Therefore, a proper mathematical model for the calculation of the peak value of the cogging torque has been realised. After numerous performed optimisations using GA and CS two new models of the permanent magnet synchronous motor, are reached. The two new proposed solutions have a smaller maximum value of the cogging torque concerning the initial model, where the Cuckoo solution has the smallest cogging torque value, followed by the GA solution and the initial solution. Finally, the three motor solutions, the initial and the two optimised solutions, have been modelled and analysed using the Finite Element Analysis approach using the software Infolytica particularly the programme Motor-solve. The analytically determined values of the cogging torque during optimisation process have been verified with the values gained from the finite element analysis (FEA) and they are in good agreement. This proves that the mathematical model for the determination of the maximum value of the cogging torque is correct and that the optimisation procedure is appropriate for such an application. Using the FEA software additional characteristics for all three investigated models have been determined. In that sense, besides the cogging torque, the following characteristics were determined: air-gap flux density distribution, magnetic field distribution for rated load, flux-current characteristics, torque characteristics, torque-speed characteristics and efficiency map. Based on those presentations certain conclusions were drawn for each characteristic separately. Finally, regarding all the presented data and characteristics it is concluded that besides a reduction of the peak cogging torque value slight improvement can be noticed on the other presented characteristics as well.

Further improvements of this approach can be done by reinvestigating the definition of the upper and lower bounds of the optimisation parameters, as well as defining some additional constraints or taking into account additional parameters to reach even smaller values for the peak value for the cogging torque. In the near future ,the authors plan to extend their research work using multi-objective (Cvetkovski and Petkovska, 2016; Jensen et al., 2019; Lei et al., 2021) or many-objective approach (Deb and Jain, 2014) in the stochastic search for the optimal solution of the permanent magnet synchronous motor. With this approach, the specific motor parameter such as efficiency, specific power rate, cogging torque, the total motor mass of iron, copper and permanent magnet material, etc. can be confronted and taken into consideration in a wider optimisation search. Such a variety of solutions then can be additionally analysed using the Pareto approach (Di Barba et al., 2019).

\section{References}

Ackermann, B., Janssen, J. H., Sottek, R. and Van Steen, R. I. (1992). New Technique for Reducing Cogging Torque in a Class of Brushless DC Motors. IEE Proceedings of Electric Power Applications, 139(4), pp. 315-320.

Benlamine, R., Dubas, F., Randi, S. A., Lhotellier, D. and Espanet, C., (2013). Design by Optimization of an Axial-Flux Permanent-Magnet Synchronous Motor Using Genetic Algorithms. 2013 International
Conference on Electrical Machines and Systems (ICEMS), 23-26, pp. 13-17.

Bianchi, N. and Bolognani, S. (2002). Design Techniques for Reducing the Cogging Torque in Surface-Mounted PM Motors. IEEE Transactions on Industry Applications, 38(5), pp. 1259-1265.

Bianchi, N. and Bolognani, S. (2000). Reducing Torque Ripple in PM Synchronous Motors by Pole Shifting. 
Proceedings of the International Conference on Electrical Machines ICEM, 28-30, pp. 1222-1226.

Chitara, D., Niazi, K. R., Swarnkar, A., and Gupta, N., (2018). Cuckoo Search Optimization Algorithm for Designing of a Multimachine Power System Stabilizer. IEEE Transactions on Industry Applications, 54(4), pp. 3056-3065.

Cvetkovski, G. and Petkovska, L. (2016). Multi-Objective Approach of Design Optimization of Axial Flux Permanent Magnet Motor. International Journal of Applied Electromagnetics and Mechanics, 51(s1), pp. S115-S123.

Cvetkovski, G. and Petkovska, L. (2021). Cogging Torque Minimization of PM Synchronous Motor Using Nature Based Algorithms. IEEE International Power Electronics and Motion Control Conference IEEE PEMC2020, 25-29, pp. 419-425.

Deb, K. and Jain, H. (2014). An Evolutionary ManyObjective Optimization Algorithm Using ReferencePoint Based Non-dominated Sorting Approach, Part I: Solving Problems With Box Constraints, IEEE Transactions on Evolutionary Computation, 18(4), pp. 577-601.

Deodhar, R. P. Stanton, D. A. Jahns, T. M. and Miller, T. J. (1996). Prediction of Cogging Torque Using the Flux-MMF Diagram Technique. IEEE Transactions on Industry Application, 32(3), pp. 569-575.

Di Barba, P., Mognaschi, M. E., Rezaei, N., Lowther, D. A. and Rahman, T. (2019). Many-Objective Shape Optimisation of IPM Motors for Electric Vehicle Traction. International Journal of Applied Electromagnetics and Mechanics, 60(S1), pp. S149-S162.

Eom, J. B., Hwang, S. M., Kim, T. J., Jeong, W. B. and Kang, B. S. (2001). Minimization of Cogging Torque in Permanent Magnet Motors by Teeth Pairing and Magnet Arc Design Using Genetic Algorithm. Journal of Magnetism and Magnetic Materials, 226-230(2), pp. 1229-1231.

Fei, W. and Luk, P. C. (2010). A New Technique of Cogging Torque Suppression in Direct-Drive Permanent-Magnet Brushless Machines. IEEE Transactions on Industry Applications, 46(4), pp. 1332-1340.

Gieras, J. F. (2004). Analytical Approach to Cogging Torque Calculation of PM Brushless Motors. IEEE Transactions on Industry Applications, 40(5), pp. 1310-1316.

Goto, M. and Kobayashi, K. (1983). An Analysis of the Cogging Torque of a DC Motor and a New Technique of Reducing the Cogging Torque. Electrical Engineering Japan, 103(5), pp. 113-120.
Ho, S. L., Chen, N. and Fu, W. N. (2010). An Optimal Design Method for the Minimization of Cogging Torques of a Permanent Magnet Motor Using FEM and Genetic Algorithm. IEEE Transactions on Applied Superconductivity, 20(3), pp. 861-864.

Holland, J. H. (1995). Adaptation in Natural and Artificial Systems. Ann Arbor: University of Michigan Press.

Infolytica, User's manual, Infolytica Corporation,Wappenham, 2016.

Ishikawa, T. and Slemon, G. R. (1993). A Method of Reducing Ripple Torque in Permanent Magnet Motors Without Skewing. IEEE Transactions on Magnetics, 29(2), pp. 2028-2031.

Islam, M. S., Mir, S. and Sebastian, T. (2004). Issues in Reducing the Cogging Torque of Mass-Produced Permanent-Magnet Brushless DC Motor. IEEE Transactions on Industry Applications, 40(3), pp. 813-820.

Jensen, W. R., Pham, T. Q. and Foster, S. N. (2019). Comparison of multi-objective optimization methods applied to electrical machine design. In: K. Deb, eds., Evolutionary Multi-Criterion Optimization. Cham: Springer, pp. 719-730.

Kamal, C., Thyagarajan, T., Selvakumari, M. and Kalpana, D., (2017). Cogging Torque Minimization in Brushless DC Motor Using PSO and GA Based Optimization. 2017 Trends in Industrial Measurement and Automation (TIMA), pp. 1-5.

Kang, G. H. and Hur, J. (2005). Analytical Prediction and Reduction of the Cogging Torque in Interior Permanent Magnet Motor. IEEE International Conference on Electric Machines and Drives, pp. 1620-1624.

Kumar, A. and Chakarverty, S. (2011). Design Optimization for Reliable Embedded System Using Cuckoo Search. 2011 3rd International Conference on Electronics Computer Technology, 1, pp. 264-268.

Lei, G., Bramerdorfer, G., Ma, B., Guo, Y. and Zhu, J. (2021). Robust Design Optimization of Electrical Machines: Multi-Objective Approach. IEEE Transactions on Energy Conversion, 36(1), pp. 390-401.

$\mathrm{Li}$, T. and Slemon, G. (1988). Reduction of Cogging Torque in Permanent Magnet Motors. IEEE Transactions on Magnetics, 24(6), pp. 2901-2903.

Lukaniszyn, M., Jagiela, M. and Wrobel, R. (2004). Optimization of Permanent Magnet Shape for Minimum Cogging Torque Using a Genetic Algorithm. IEEE Transactions on Magnetics, 40(2), pp. 1228-1231.

Ma, G., Qiu, X., Yang, J., Bu, F., Dou, Y. and Cao, W. (2018). Structural Parameter Optimization to 
Reduce Cogging Torque of the Consequent Pole In-Wheel Motor. 2018 IEEE 18th International Power Electronics and Motion Control Conference (PEMC), pp. 170-175.

Mirahki, H., Moallem, M. and Rahimi, S. A. (2014). Design Optimization of IPMSM for $42 \mathrm{~V}$ Integrated Starter Alternator Using Lumped Parameter Model and Genetic Algorithms. IEEE Transactions on Magnetics, 50(3), pp. 114-119.

Mirjalili, S., Dong, J. S. and Lewis, A. (2020). NatureInspired Optimizers-Theories, Literature Reviews and Applications. Springer, Cham, Switzerland.

Motor Solve, User's manual, Infolytica Corporation, Wappenham 2016.

Quintal-Palomo, R., Dybkowski, M. and Qwoździewicz, M. A. (2016). Parametric Analysis for the Design of a 4 Pole Radial Permanent Magnet Generator for Small Wind Turbines. Power Electronics and Drives, 36(2), pp. 175-186.

Siregar, M., Mohamed, T. Z., Wohon, D. R. and Nur, T. (2019). Optimizing the Cogging Torque Reduction of Integral Slot Number in Permanent Magnet Machine. 2019 International Conference on Technologies and Policies in Electric Power \& Energy, pp. 1-5.

Sun, S., Jiang, F., Li, T. and Yang, K. (2019). Optimization of Cogging Torque in a Hybrid Axial and Radial Flux
Permanent Magnet Machine. 22nd International Conference on Electrical Machines and Systems (ICEMS), pp. 1-5.

Uler, G. F., Mohammed, O. A. and Koh, C. S. (1995). Design Optimization of Electrical Machines Using Genetic Algorithms. IEEE Transactions on Magnetics, 31(3), pp. 2008-2011.

Wu, L. J., Zhu, Z. Q., Staton, D. A., Popescu, M. and Hawkins, D. (2012). Comparison of Analytical Models of Cogging Torque in Surface-Mounted PM Machines. IEEE Transactions on Industrial Electronics, 59(6), pp. 2414-2425.

Yang, X. S. (2014). Nature-Inspired Optimization Algorithms. Elsevier, London.

Yang, X. S. and Deb, S. (2010). Engineering optimization by Cuckoo Search. International Journal of Mathematical Modelling and Numerical Optimization, 1(4), pp. 330-343.

Zarko, D., Ban, D., and Lipo, T. A. (2008). Analytical Solution for Cogging Torque in Surface Permanent-Magnet Motors Using Conformal Mapping. IEEE Transactions on Magnetics, 44(1), pp. 52-65.

Zhu, Z. Q. and Howe, D. (2000). Influence of Design Parameters on Cogging Torque in Permanent Magnet Machines. IEEE Transactions on Energy Conversion, 15(4), pp. 407-412. 